\title{
EVALUATING THE PLACE OF FERTILIZER NITROGEN FOR DAIRY FARMING
}

\section{BRownE}

The Agricultural Institute, Moorepark, Fermoy, Co. Cork, Ireland

AREAS in which white clover grows reasonably well have the potential of carrying a certain stocking rate without using fertilizer nitrogen. The development of dairying in such areas will logically use the best available legumes to increase stock carrying capacity to its economic optimum. Evaluating the place of fertilizer nitrogen in these areas will therefore be concerned with the establishment of the maximum economic production from legume-based pastures, and secondly with the increase in production per unit area possible using a range of nitrogen levels. Where the research objective is to provide guidance to a developing. industry, the optimum production from both nitrogen, sources must be defined using available information on the best management systems, most suitable legumes, most effective rhizobium, etc. This approach accepts that new information on any of the factors involved could increase the stocking rate which gives optimum production from either nitrogen source and would advocate that some of the research resources should be used to examine such management factors. If this guidance is not available, decisions will still have to be made by the industry but at greater risk (Morley and Spedding, 1968).

\section{RESEARCH APPROACH}

Cutting trials preferably using animals as defoliators can first be used to record dry matter production. Where small differences in dry matter yield are obtained, animal experimentation is hardly justified. Where the increases obtained in dry matter yield when converted using conventional values to animal production indicate 'the possibility of increased profitability, then the priority of animal experimentation is increased. This paper discusses the design and interpretation of such animal experiments using examples from Irish research where the effect of applying different levels of nitrogen to grass/clover swards is being examined. 
Steers normally require fewer facilities than dairy cows and consequently can be used to define more points on the nitrogen response curve for the same input of resources. The treatments used and results of one experiment where steers were used are given in Table 1.

TABLE 1: NITROGEN LEVELS, STOCKING RATES AND LIVEWEIGHT GAINS

\begin{tabular}{cccc}
\hline $\begin{array}{c}\text { Nitrogen } \\
\text { Applied } \\
\text { (lb/acre) }\end{array}$ & $\begin{array}{c}\text { Stocking } \\
\text { (steers/acre) }\end{array}$ & $\begin{array}{c}\text { Rateweight } \\
\text { (lb/steer) }\end{array}$ & $\begin{array}{c}\text { Gain } \\
\text { (lb/acre) }\end{array}$ \\
\hline 0 & 1.76 &, 320 & 563 \\
0 & 2.01 & 295 & 593 \\
0 & 2.26 & 227 & 513 \\
200 & 1.74 & 396 & 689 \\
200 & 2.05 & 366 & 750 \\
200 & 2.29 & 340 & 779 \\
200 & 2.66 & 260 & 692 \\
\hline
\end{tabular}

S.E. of treatment means \pm 81 .

Two nitrogen levels 0 and 200 lb/acre were examined at different stocking rates. The pasture was a permanent sward which had received basic fertilizers for 6 years prior to this comparison. Twelve steers were used per treatment. Grazing management was identical for all treatments. Each treatment had 5 paddocks. On both nitrogen levels the stocking rates selected were sufficiently high to exceed the point of maximum production per unit area. These data can be used to estimate the response to nitrogen.

One estimate of the difference between treatments is the difference between stocking rates where liveweight gains per animal are not significantly different provided both are depressed to a level below that possible on unrestricted intake.

The second and most realistic method is to compare treatments at their optimum stocking rates, optimum stocking rate being defined as that which gives the maximum production per unit area of a defined product. Since optimum stocking rates are unknown, these comparisons cannot be made directly; instead, they must be inferred from the results obtained with the stocking rates used. This requires that some form of a production stocking rate relationship be used. Conniffe et al. (1970) suggested that 
this production stocking rate relationship may be represented in their environment by the equation

$$
Y=A-r[(c-\chi) / c]^{2}
$$

where $\mathrm{Y}=$ production per animal

$\mathrm{A}=$ production per animal at unrestricted intake

$\mathbf{r}=$ constant for particular experimental site and animals

c = smallest area per animal compatible with unrestricted intake

$x=$ area per animal

Using this equation, the comparison of treatments is expressed as the ratio of their optimal yields per unit area. The limited data available suggest that greatest accuracy is obtained with this equation when the stocking rates used result in large depression in animal performance. Using this equation, the optimal yield of the sward receiving nitrogen was calculated to be $31 \%$ higher than the sward not receiving nitrogen (Table 1).

In this type of experimentation where three stocking rates are used, optimum stocking rate can be calculated if two are sufficiently high to depress animal performance. Three stocking rates per treatment permit valid treatment comparisons and error estimates for the comparisons. If all three stocking rates are high enough to depress animal performance, then tests of the assumptions used in the analysis can be performed (Conniffe et al., 1970).

\section{"WHOLE FARM" EXPERIMENTS}

The same principles apply to "whole farm" experiments whether beef or lactating animals are used. The treatments and stocking rates used in one such "whole farm" dairying study are shown in Table 2. It is advisable to locate

TABLE 2: EXPERIMENTAL DESIGN

\begin{tabular}{ccc}
\hline & Treatment & $\begin{array}{c}\text { Stocking Rate } \\
\text { (acres/cow) }\end{array}$ \\
\hline A & Basic $+50 \mathrm{lb} \mathrm{N} /$ acre & 1.22 \\
for silage & \\
B & $n$ & 1.03 \\
C & Basic +200 lb N/acre & 0.85 \\
E & $"$ & 0.94 \\
F & $"$ & 0.80 \\
\hline
\end{tabular}


these "whole farm" experiments in representative regions selected on the basis of soil classification and climate because regions differing in soil type and climate are likely to have different optimum stocking rates. This study is located on a representative free-draining soil. Twenty Friesian type cows are used per treatment. Grazing management is identical on all treatments. The principal management factors include seasonal calving (3-month period), minimal concentrate feeding $(200 \mathrm{lb}$ per cow or less) conserving the same proportion of all treatments as silage and the feeding of the silage to the cows on their respective treatments. The same system of rotational grazing is practised on all treatments. The management system adopted is that recommended to and used by dairy farmers who are increasing stock numbers. Using this design, the optimum stocking rates on both nitrogen levels can be determined and thus the profitability of the higher nitrogen level for that location.

The pattern of results obtained in Ireland using these designs were as follows:

(1) The application of $200 \mathrm{lb}$ nitrogen per acre increased stock carrying capacity by approximately $30 \%$. These results were obtained on swards where the pattern of clover growth was similar to that shown in Fig. 1. The clover content of the control treatment influenced the response to applied nitrogen (Browne, 1966).

(2) Further increases in stocking rate were not obtained when higher levels of nitrogen were used.

(3) An inverse relationship between nitrogen application and clover content was found in all experiments. Where $200 \mathrm{lb}$ nitrogen per acre was applied, the percentage clover in grazed swards was seldom greater than five. When nitrogen application was discontinued, clover rapidly developed in the sward. In almost all cases studied, differences in clover content disappeared within one grazing season irrespective of previous nitrogen use, with the exception of areas where high rates of sulphate of ammonia were used. Of more importance is the fact that, in the first year that nitrogen application was discontinued, there were no differences in animal production per acre irrespective of previous nitrogen use. This interchangeability of nitrogen source permits flexibility in the use of clover or fertilizer nitrogen on a year to year basis. This is important when the response to $200 \mathrm{lb}$ nitrogen per acre is 


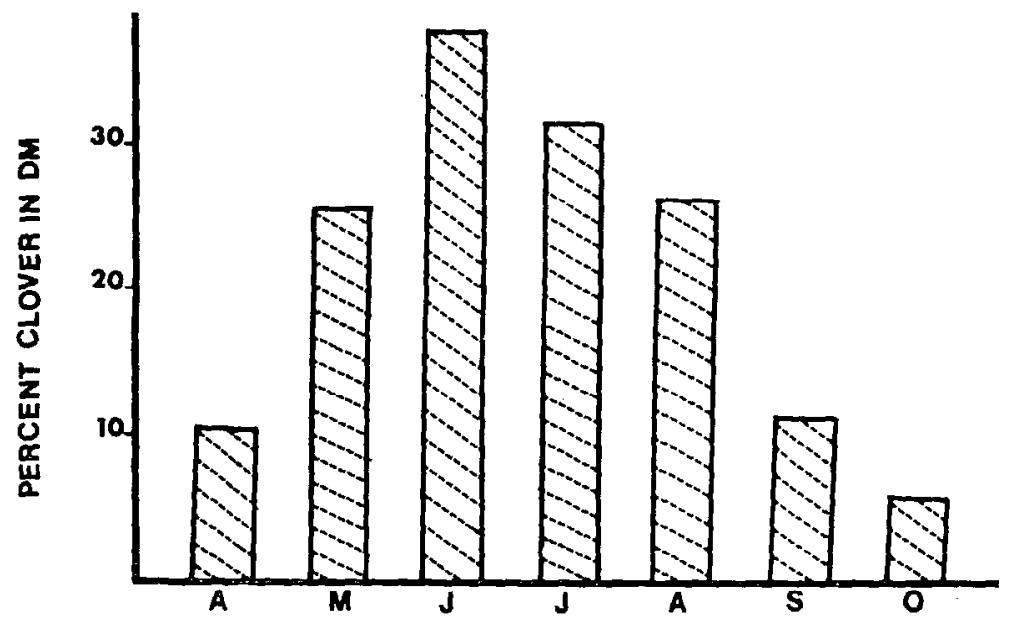

FIG. 1: The normal pattern of clover growth over the April-0 ctober period.

approximately $30 \%$ because relatively small changes in product price can seriously alter the economics of nitrogen use. These results are specific to the Irish environment and obviously because of the many factors involved extrapolation to other environments is not likely to be valid.

\section{FUTURE EXPERIMENTATION}

The overall objective on both grass/legume and nitrogenfertilized pastures is to optimize the total system--i.e., to have all components operating at optimum. This may mean that in "whole farm" experiments different levels or sources of nitrogen should be compared under different management systems. Experimentation of this type is valid only if the difference in management techniques has been shown in controlled experimentation to be advantageous for a particular treatment. If this were not so, it could result in biased treatment comparisons; indeed, if different management systems were subjectively imposed on each nitrogen level, it may be impossible to interpret the results obtained. Present knowledge would suggest that each management system for a particular nitrogen input would have to be measured with at least two but preferably three stocking rates. Facilities will rarely allow such an experiment which, for example, attempts to examine four nitrogen 
levels under three management systems each at three stocking rates. Management studies are therefore likely to be conducted on either grass/legume or nitrogenfertilized swards depending on their relative importance in a particular environment.

Management systems based on agronomic principles should lead to increased animal production per unit area. However, the results from management studies where animal output has been measured have been variable. Cutting studies have shown that increasing the intervals between cuttings increases total dry matter production on nitrogen-fertilized swards (Brockman, 1969). Better utilization of nitrogen within the plant is advanced as one of the main reasons for the increased yield. On this evidence, increasing the interval between grazings. could justifiably be expected to increase animal production per unit area. There are, however, few experimental data to support this. At Moorepark, two intervals of grazing, namely, 15 and 30 days, were compared at two stocking rates. There were 10 paddocks on each of the four treatments. Preliminary results show only small, non-significant differences between intervals. There is a suggestion of an advantage for the long interval at the high stocking rate and for the shorter interval at the low stocking rate. A fixed interval is, of course, not likely to be optimum management over a season which has a variable growth nattern. However, even *with this restriction, the longer interval produced more dry matter in cutting experiments. Further data are being collected to provide a better basis for understanding these results.

Future legume nitrogen comparisons are likely to benefit from more attention to these types of agronomic management factors. This benefit is most likely to be obtained where the animal and plant specialists, especially the plant physiologist, co-operate on grazing studies. This combination of "whole farm" and associated management studies can be expected to provide realistic guidance for the dairy industry on the source and/or level of fertilizer nitrogen to use.

\section{REFERENCES}

Brockman, J. S., 1969: J. Br. Grassld Soc., 24: 89.

Browne, D., 1966: J. agric. Res., 5: 89.

Conniffe, D.; Browne, D.; Walshe, M. J., 1970: J. agric. Sci., 74: 339.

Morley, F. H. W.; Spedding, C. R. W., 1968: Herb. Abstr. 38: 279. 


\section{DISCUSSION}

Campbell asked if animal response to management system trials depended on the kind of animal used. Browne agreed that sheep did not give such good responses as cattle. He wanted to see if the beef animal was as good in response as the dairy cow. The former's sensitivity appeared to be very similar to that of the latter. If this were indeed so, it would allow more experiments to be carried out with the same facilities. Lowe (N. Ireland) inquired whether it was valid to compare nitrogen and no-nitrogen treatments under the same grazing management. Browne stated that there was little information to support the use of different treatments. However, it might be necessary to develop systems to ascertain whether this was required. Sprague (U.S.A.) asked if Browne had considered intensity of grazing in his experiments, to which Browne replied that no work on that aspect had been done in Ireland but that he was at present considering a design to give this information. Brougham here commented that the present outlook was to consider the phenology of the plant rather than the calendar. All factors determining regrowth must be considered and animal and plant workers were gradually coming more and more together in their approach. Washko (U.S.A.) asked if any suppression of white clover by nitrogen had occurred and Browne replied that, as levels of nitrogen increased beyond 200 lb/acre there was never more than $5 \%$ of clover in the sward. However, if the use of $\mathrm{N}$ was discontinued the clover situation soon developed back to the original composition: To an inquiry from Heath (U.S.A.) as to the effect of nitrogen on animal performance, Browne stated that no differences in per animal performance at different rates of $\mathrm{N}$ had been measured in either beef or dairy cows. Nitrogen was usually applied in the form of calcium ammonium nitrate. Recent evaluation trials with urea had shown that it had $85 \%$ of the efficiency of the former. Studies were being carried out on the correct method of applying nitrogen. Normally the farmer would use 200 units, with 50 applied at the beginning of growth in the spring and then 25 units after each grazing. 